\title{
Numerical Modeling of Water and Gas Transport in Compacted GMZ Bentonite under Constant Volume Condition
}

\author{
Jiang-Feng Liu $\mathbb{D},{ }^{1,2}$ Xu-Lou Cao, ${ }^{1}$ Hong-Yang Ni $\mathbb{D}^{1},{ }^{1}$ Kai Zhang $\mathbb{D}^{1},{ }^{1}$ Zhi-Xiao Ma, ${ }^{1}$ \\ Li-Ke Ma, ${ }^{3}$ and Hai Pu ${ }^{1}{ }^{1}$ \\ ${ }^{1}$ State Key Laboratory for Geomechanics and Deep Underground Engineering and School of Mechanics and Civil Engineering, \\ China University of Mining and Technology, Xuzhou 221116, China \\ ${ }^{2}$ Key Laboratory of Geotechnical and Underground Engineering of Ministry of Education, Tongji University, Shanghai 200092, China \\ ${ }^{3}$ CNNC Beijing Research Institute of Uranium Geology (BRIUG), Beijing 100029, China
}

Correspondence should be addressed to Hong-Yang Ni; nhyang@cumt.edu.cn and Kai Zhang; kzhang@cumt.edu.cn

Received 13 August 2019; Revised 9 January 2020; Accepted 5 January 2021; Published 20 January 2021

Academic Editor: Yuanyuan Zha

Copyright ( 92021 Jiang-Feng Liu et al. This is an open access article distributed under the Creative Commons Attribution License, which permits unrestricted use, distribution, and reproduction in any medium, provided the original work is properly cited.

During deep geological disposal of high-level and long-lived radioactive waste, underground water erosion into buffer materials, such as bentonite, and gas production around the canister are unavoidable. Therefore, understanding water and gas migration into buffer materials is important when it comes to determining the sealing ability of engineered barriers in deep geological repositories. The main aim of our study is to provide insights into the water/gas transport in a compacted bentonite sample under constant volume conditions. The results of our study indicate that water saturation is obtained after 450 hours, which is similar to experimental results. Gas migration testing shows that the degree of water saturation in the samples is very sensitive to the gas pressure. As soon as $2 \mathrm{MPa}$ or higher gas pressure was applied, the water saturation degree decreased quickly. Laboratory experiments indicate that gas breakthrough occurs at $4 \mathrm{MPa}$, with water being expelled from the downstream side. This indicates that gas pressure has a significant effect on the sealing ability of Gaomizozi (GMZ) bentonite.

\section{Introduction}

At present, energy shortages are a serious problem in China. In recent years, the Chinese state has vigorously developed its nuclear power. As a result, a large amount of nuclear waste has been generated. Therefore, the management and storage of these high-level radioactive wastes (HLRW) have become an important issue ([1-3]; Liu et al., 2020a; [4]). When it comes to the final disposal of HLRW, a useful method adopted by many countries is to store these wastes in deep geological repositories, including natural geological barriers and engineered barrier systems (EBS) [1, 5-7]. A natural geological barrier is generally composed of the host rock, such as granite in China, $\mathrm{CO}_{\mathrm{x}}$ argillite in France, Opalinus clay in Switzerland, and Boom clay in Belgium. An engineered bar- rier system stores waste in repositories such as waste storage vessels and buffer/backfill material [8-11].

With respect to bentonite, at the initial stage of underground storage, it only becomes partially saturated. After disposal pits are filled up, sealing occurs gradually. Underground water seepage can lead to proper bentonite swelling and, hence, disposal pit sealing. Nevertheless, in the longterm, gases may be produced in a bentonite repository due to several reasons, such as humid corrosion, water radiolysis, and organic waste microbial degradation [12-14]. In the initial stage, the gas pressure is low, and groundwater intrusion is dominant. Therefore, the bentonite barrier gradually becomes saturated. With time, generated gases may not escape and, therefore, accumulate in the space between the canister and the clay barrier. The accumulation of gas can 


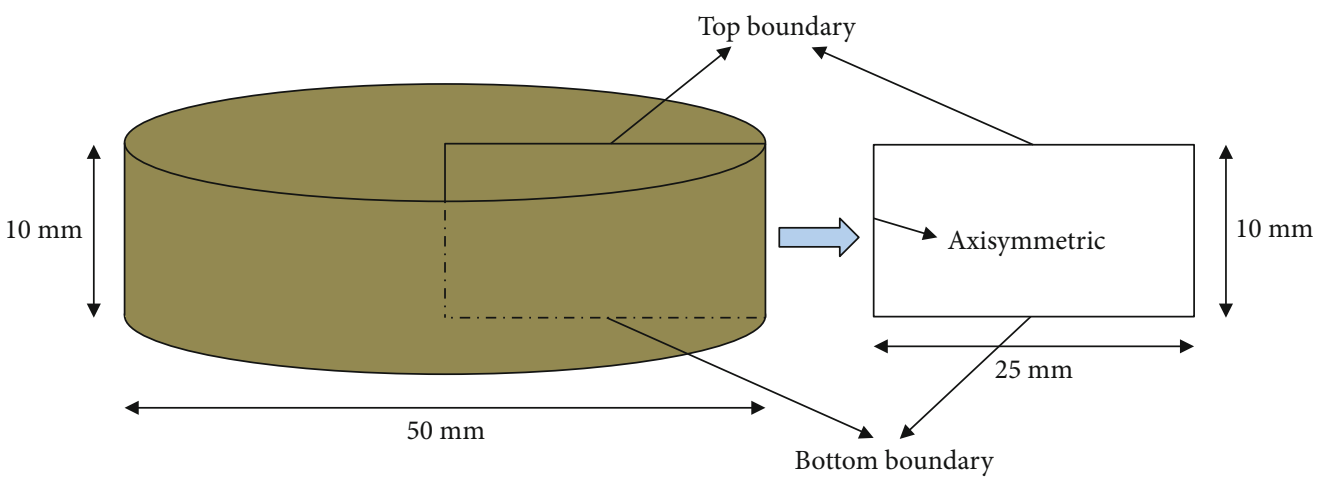

(a)
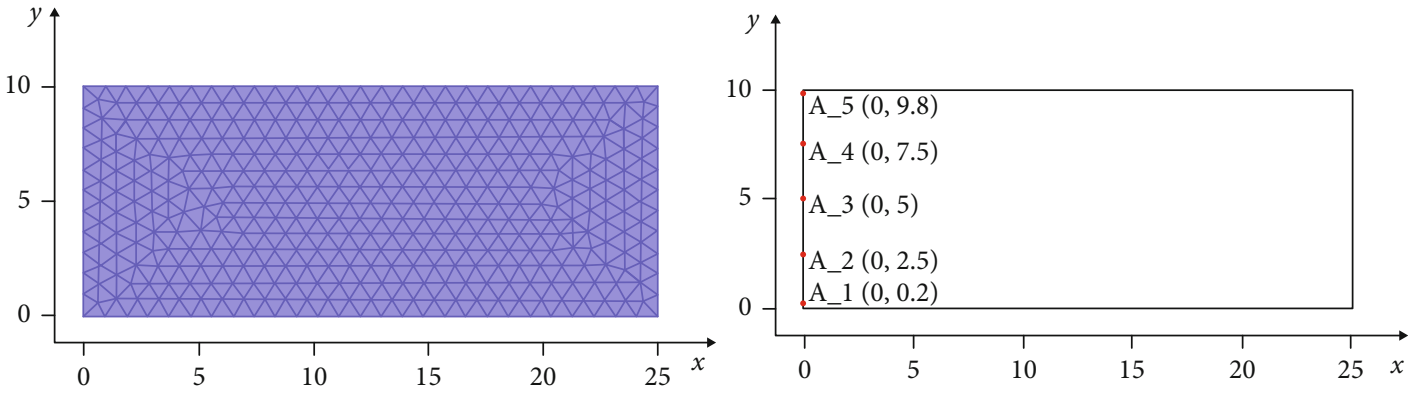

(b)

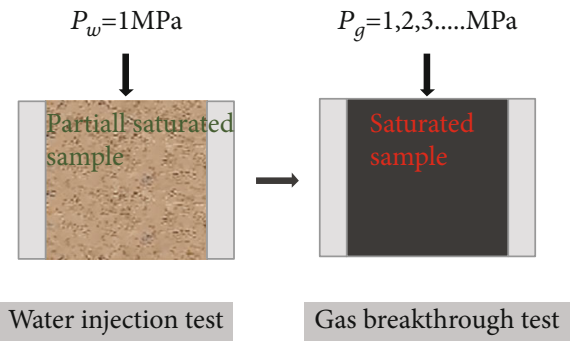

(c)

Figure 1: (a) Geometric model and finite element mesh. (b) Modelling scheme. (c) Water and gas injection test.

TABLE 1: Numerical model parameters.

\begin{tabular}{lccc}
\hline Parameters & Symbols & Units & Values \\
\hline Residual saturation & $S_{r}$ & -- & 0 \\
Maximum saturation & $S_{\max }$ & -- & 0.999999 \\
Water density & $\rho_{\omega}$ & $\mathrm{kg} / \mathrm{m}^{3}$ & 1000 \\
Water permeability & $K_{\omega}$ & $\mathrm{m}^{2}$ & $2.30 \times 10^{-20}$ \\
Porosity & $\varphi$ & -- & 0.34 \\
Van Genuchten's parameters & $n$ & -- & 1.27 \\
Van Genuchten's parameters & $m=1-1 / n$ & -- & 0.21 \\
Van Genuchten's parameters & $P_{r}$ & $\mathrm{~Pa}$ & 990000 \\
Perfect gas constant & $R$ & -- & 8.3144 \\
Temperature & $T$ & $\mathrm{~K}$ & 295 \\
Molar volume & $v_{m}$ & $\mathrm{Mol} / \mathrm{L}$ & $1.80 \mathrm{E}-05$ \\
\hline
\end{tabular}

lead to overpressurization of the EBS, especially the compacted bentonite barrier. When gas pressure exceeds a certain value, the gas breakthrough occurs, and gas pressure decreases. This process will be accompanied by the evolution of the bentonite barrier from saturated to unsaturated.

Gas pressure and water pressure are a competitive relationship in the pore network of bentonite. The accumulated gas pressure will affect the migration of groundwater in the pore network of the bentonite block, thereby affecting its sealing performance. In addition, the nuclides themselves cannot be migrated, and the migration of nuclides is essentially due to the migration of groundwater gas in the soil/rock matrix. Therefore, it is important to adequately study the water/gas migration in bentonite barriers to assess the longterm performance of these barriers and to verify the feasibility and safety of such repositories.

The sealing ability of bentonite barriers is not very clear. Further work is required to study how to quantitatively evaluate the sealing ability of bentonite barriers. Many previous studies have used gas permeability as an evaluation indicator [15-19]. However, this approach is not sufficient for unsaturated 


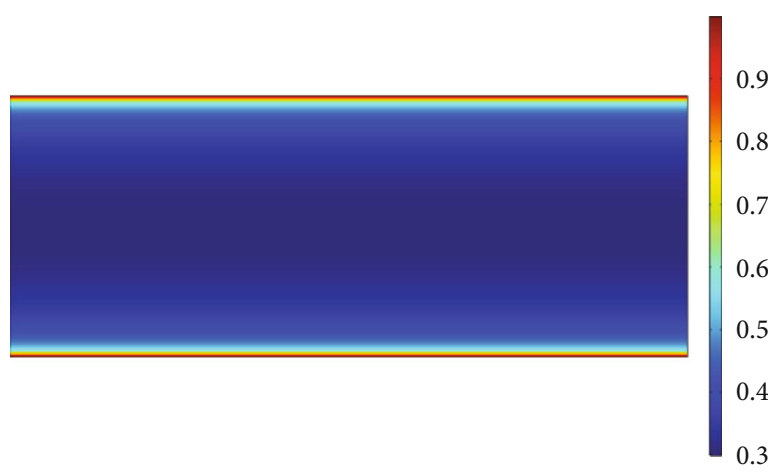

(a)

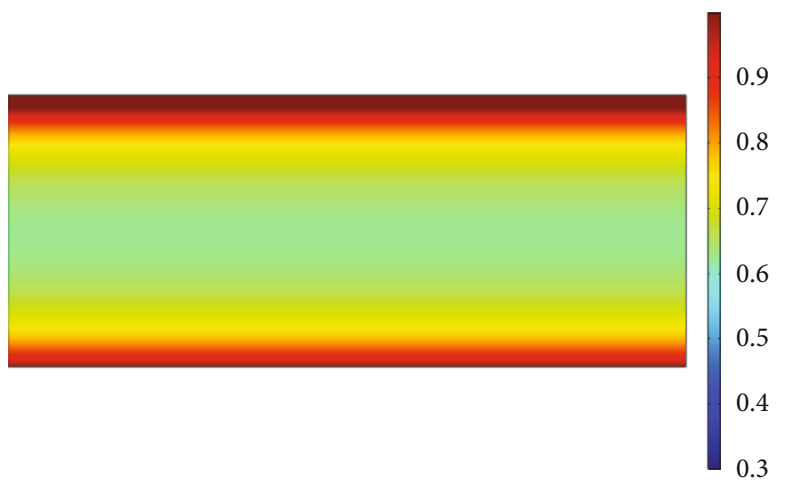

(c)

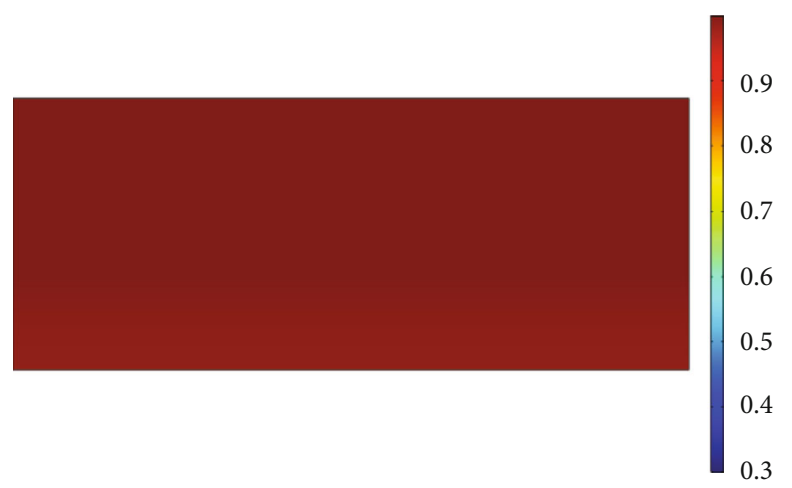

(e)

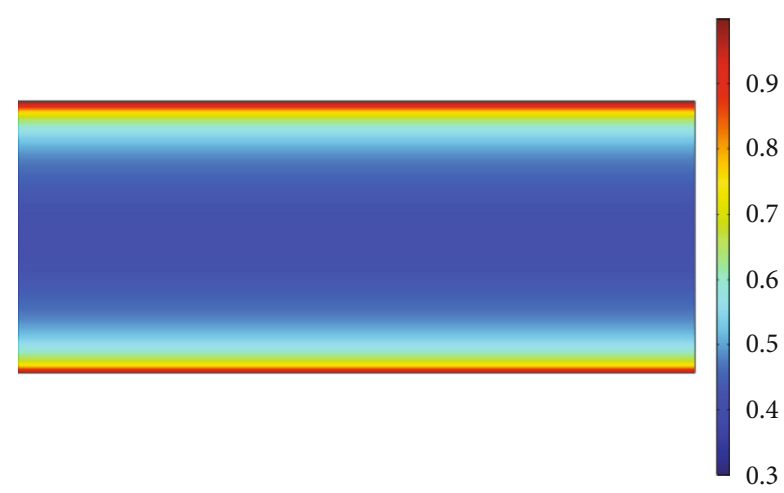

(b)

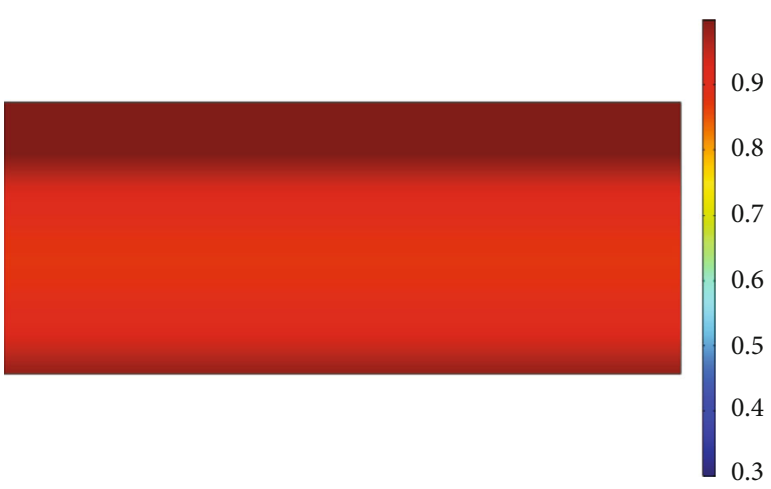

(d)

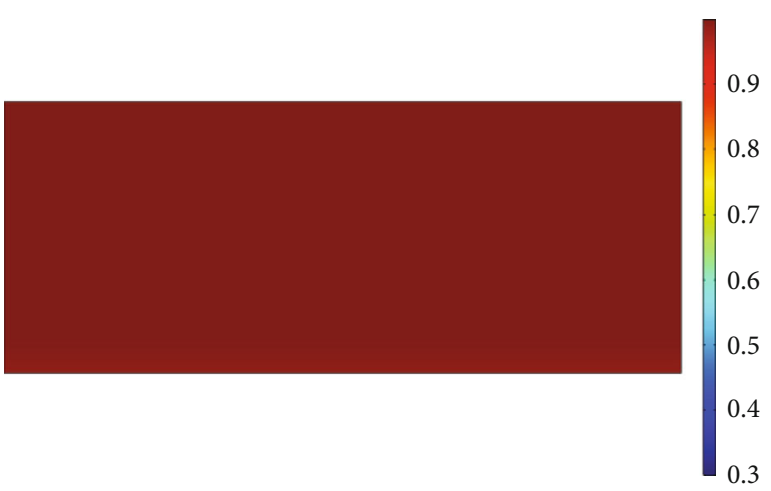

(f)

Figure 2: Evolution of water saturation at $P_{w}=1 \mathrm{MPa}$ (a) $t=1 \mathrm{~d}$, (b) $t=5 \mathrm{~d}$, (c) $t=10 \mathrm{~d}$, (d) $t=15 \mathrm{~d}$, (e) $t=20 \mathrm{~d}$, and (f) $t=25 \mathrm{~d}$.

materials because of their high gas permeability. For saturated (or nearly saturated) clayey materials, gas permeability can be as low as $10^{-21} \mathrm{~m}^{2}$, which is difficult to measure. In addition, Darcy's law is usually not suitable in this situation. Therefore, other researchers have used gas breakthrough pressure to evaluate the sealing efficiency of clayey barriers ([11, 20-22] and 2020c; [23]). The so-called gas breakthrough pressure can be explained as follows. Gas pressure is increased step by step at the upstream side of the sample until discontinuous/continuous gas flow is detected at the other side. The corresponding gas injection pressure is defined as the discontinuous/continuous gas breakthrough pressure [24]. Some studies indicate that the gas breakthrough/migration property has a close relationship with the water saturation degree. This means that the sealing ability of the clayey barrier relies on its gas permeability and water saturation degree. However, it is difficult to obtain the water saturation of a sample during the gas injection test in laboratory experiments since the sample can only be removed from the triaxial cell at the end of the test. Therefore, numerical modeling is an effective method in such instances. In addition, numerical modeling allows us to clearly obtain the saturation degree at different locations of the sample. Therefore, in this study, a series of numerical modeling operations were performed to compare their results with those from laboratory experiments.

\section{Mathematical Formulation}

2.1. Liquid Flow Equations. Richards's equation describes the flow in an unsaturated medium [25-27]:

$$
\frac{\partial w_{\omega}}{\partial t}=\operatorname{di\tau }\left(K\left(\nabla P+G^{m}\right)\right)
$$




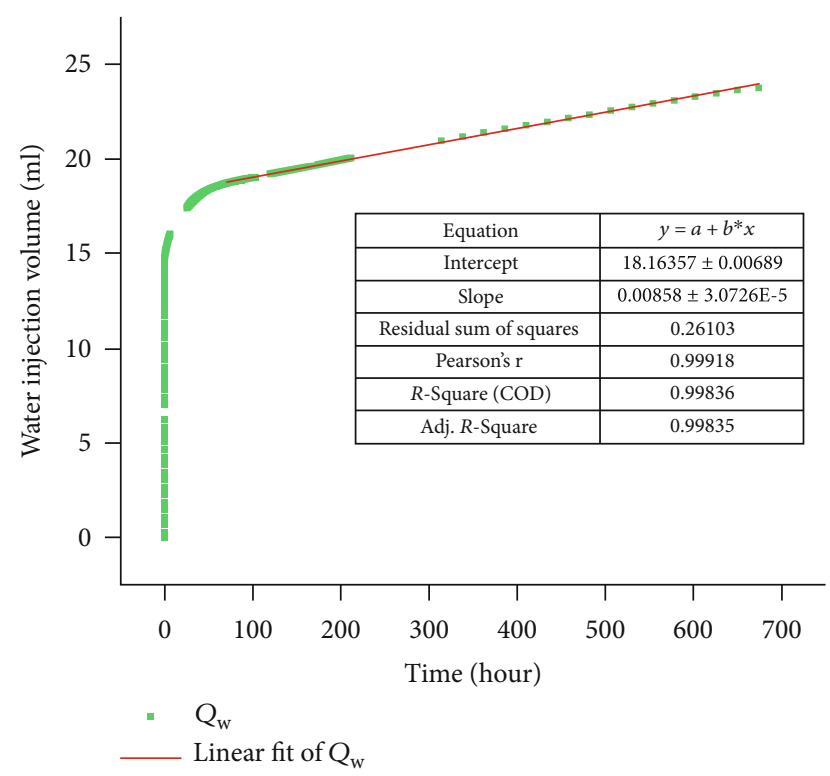

FIgURE 3: Water-injection test (experimental data).

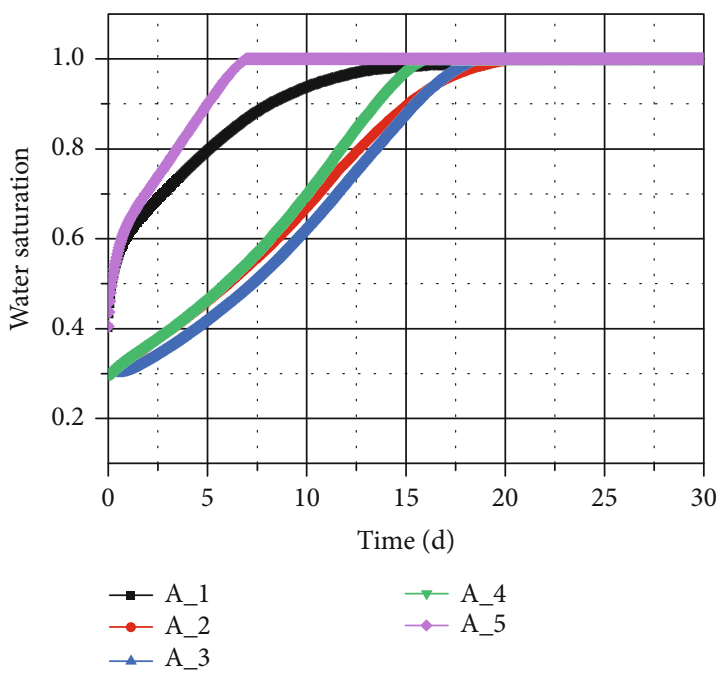

Figure 4: Evolution of the water saturation of the monitoring points as a function of time (numerical modeling).

where $w_{\omega}$ is the volume water content, $t$ is the time, $K$ is the hydraulic conductivity, $P$ is the hydraulic pressure, and $G^{m}$ is the vector of gravity (the values are -1 and 1 for the vertical direction and the horizontal direction, respectively). Effective water saturation $S_{w}$ can be obtained as follows:

$$
S_{\omega}=\frac{w_{\omega}-\theta w_{\gamma}}{\mathrm{w}_{s}-w_{\gamma}}
$$

where $w_{\gamma}$ is the residual water content, and $w_{s}$ is the saturated water content (i.e., 1.0). Using equation (2), we can rewrite equation (1) as

$$
\frac{\partial S_{\omega}}{\partial t}=\frac{1}{\varphi} \operatorname{di\tau }\left(\frac{K_{\omega . i} K_{\omega . r}}{\mu_{\omega}}\left(\nabla p_{\omega}+\rho_{\omega} g G^{m}\right)\right),
$$

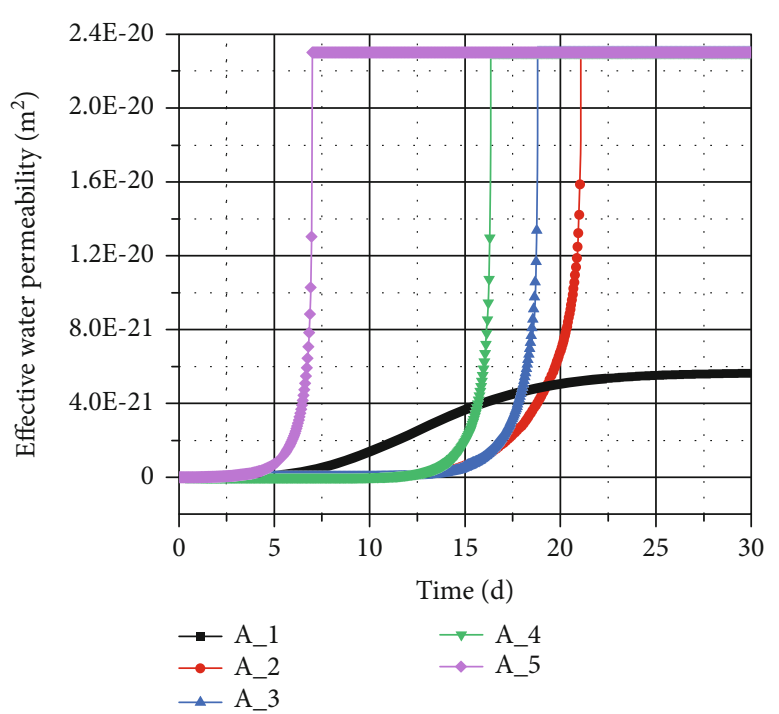

FIGURE 5: Evolution of water permeability of the monitoring points.

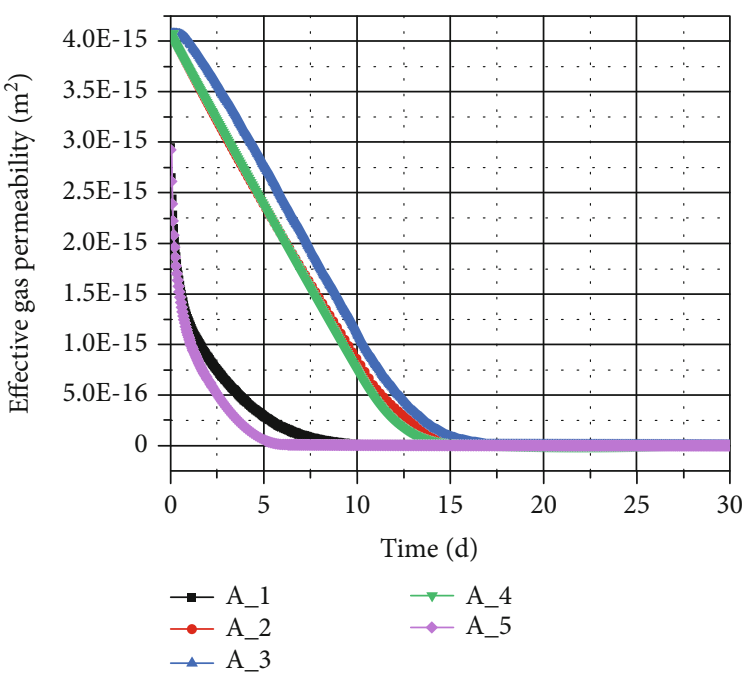

Figure 6: Evolution of gas permeability of the monitoring points.

where $\varphi=w_{s}-w_{\gamma}$ is the apparent porosity in water, and the water content is defined by the ratio of the water volume to the sample volume; $K_{\omega . i}$ and $K_{\omega . r}$ are the water permeability and the relative water permeability, respectively, $\mu_{\omega}$ is the water viscosity, $\rho_{\omega}$ is the water density, $g$ is the gravitational acceleration, and $P_{\omega}=\rho_{\omega} h g$ is the water pressure. For the unsaturated case, $P_{\omega}=P_{g}-P_{c}, p_{g}$, and $P_{c}$ are the gas pressure and capillary pressure, respectively.

In equation (3), $S_{\omega}, K_{\omega . r}$, and $P_{c}$ are three unknown parameters, where $K_{\omega . i}$ and $\varphi$ are constant and can be directly determined by laboratory experiments, and $\mu_{\omega}$ is equal to $1.0 \times 10^{-3} \mathrm{~Pa}$.s. Therefore, two additional equations are required to solve Equation (3).

2.2. Capillary Pressure and Relative Permeability. The relationship between capillary pressure $P_{c}$ and relative humidity $\mathrm{RH}$ is described by the Kelvin-Laplace equation. The relative 


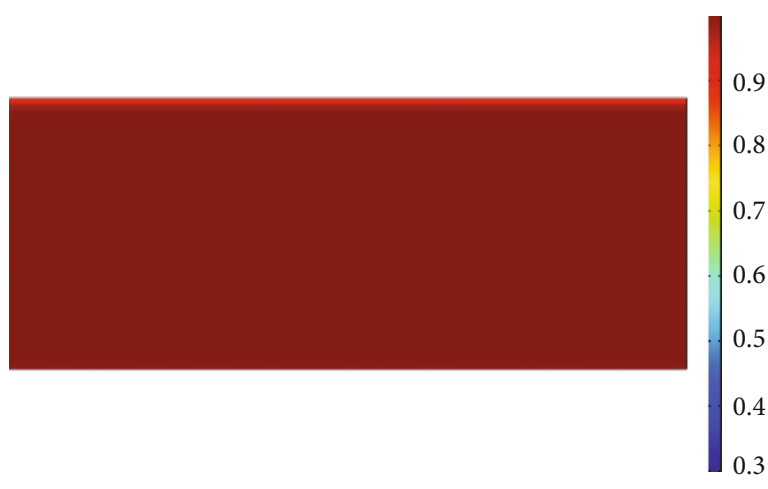

(a)

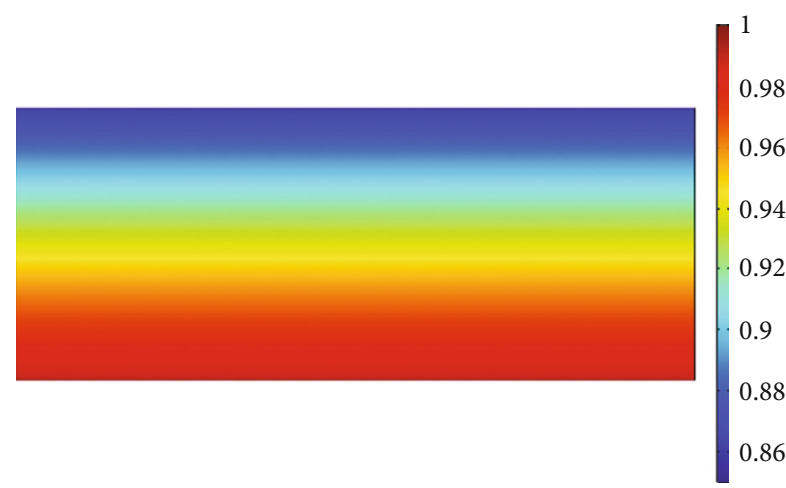

(c)

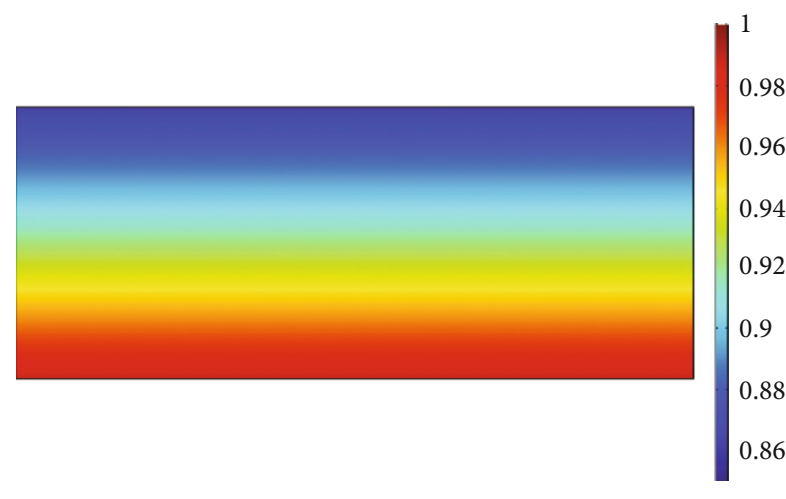

(e)

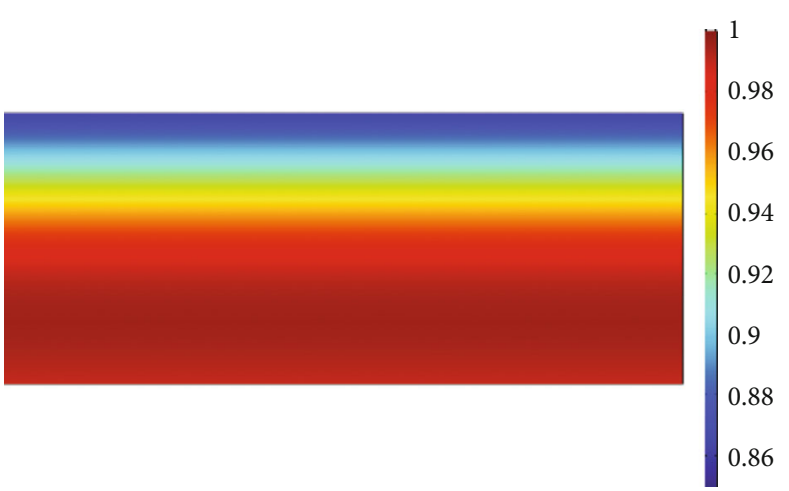

(b)

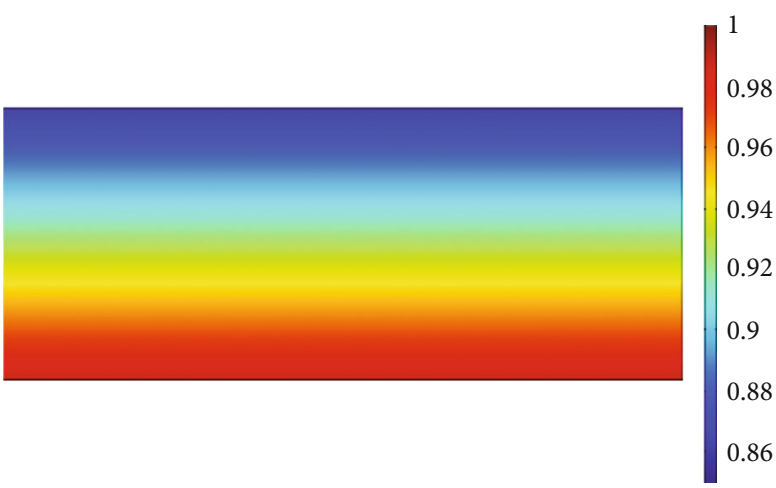

(d)

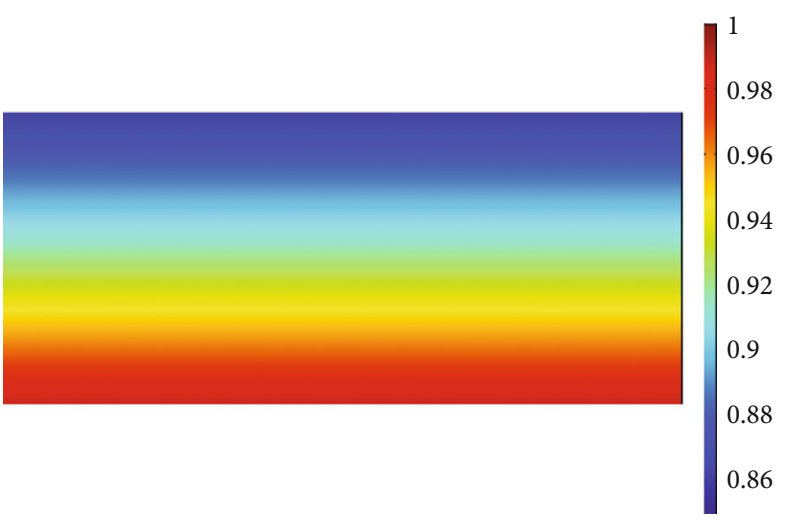

(f)

Figure 7: Evolution of water saturation at $P_{g}=1 \mathrm{MPa}$ (a) $t=0 \mathrm{~d}$, (b) $t=4 \mathrm{~d}$, (c) $t=8 \mathrm{~d}$, (d) $t=12 \mathrm{~d}$, (e) $t=16 \mathrm{~d}$, and (f) $t=20 \mathrm{~d}$.

humidity of the air above the meniscus in a capillary pore is given by the Kelvin equation and Young-Laplace equation [28-30]:

$$
P_{c}=-\frac{R T}{v_{m}} \ln (\mathrm{RH})
$$

where $v_{m}$ is the molar volume, $R$ is the universal gas constant, and $T$ is the temperature.

The Van Genuchten (VG) model [31] describes the relationship between water saturation $S_{\omega}$ and the capillary pressure $P_{c}$,

$$
S_{w}=\left(1+\left(\frac{P_{c}}{P_{r}}\right)^{n}\right)^{-m},
$$

where $m=1-1 / n$ and $P_{r}$ are two parameters that are related to the pore size distribution of the porous medium. To determine the two parameters, the samples were put in different desiccators to obtain different water content. Then, the degree of saturation was calculated, and its relationship with relative humidity was obtained. Finally, the two parameters could be determined by the least-squares method. Regarding the relative permeability, which is given by the Mualem model [32]: 


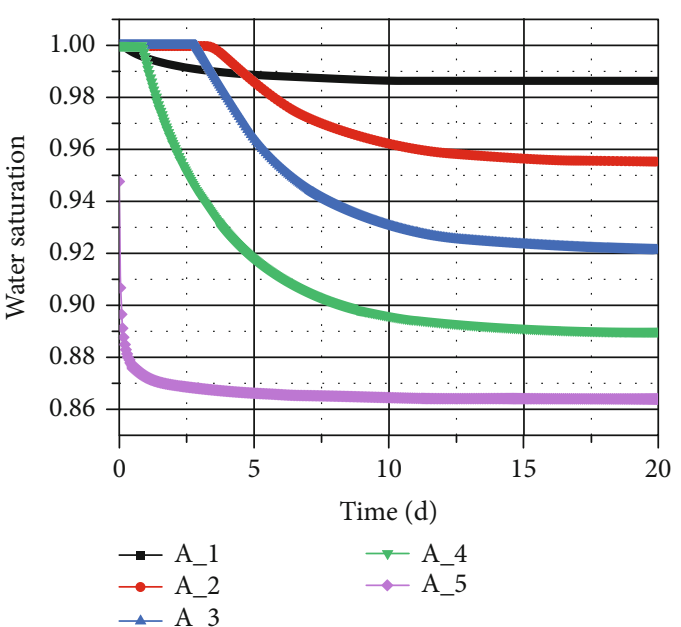

FIGURE 8: Evolution of the water saturation degree of the monitoring points as a function of time.

$$
\begin{gathered}
K_{w, r}=S_{w, j}^{1 / 2}\left(\frac{\int_{0}^{S_{w, j}}\left(d S_{w} / P_{c}\right)}{\int_{0}^{1}\left(d S_{w} / P_{c}\right)}\right)^{2}, \\
K_{g, r}=\left(1-S_{w, j}^{1 / 2}\right)\left(\frac{\int_{0}^{S_{w, j}}\left(d S_{w} / P_{c}\right)}{\int_{0}^{1}\left(d S_{w} / P_{c}\right)}\right)^{2} .
\end{gathered}
$$

According to the Van Genuchten model, Equations (6) and (7) can be rewritten as follows:

$$
\begin{gathered}
K_{w, r}=S_{w, j}^{1 / 2}\left(1-\left(1-S_{w, j}^{1 / m}\right)^{m}\right)^{2}, \\
K_{g, r}=\left(1-S_{w, j}\right)^{1 / 2}\left(1-\left(1-S_{w, j}^{1 / m}\right)^{m}\right)^{2 m} .
\end{gathered}
$$

Additionally, in this study, the temperature was controlled at $20^{\circ} \mathrm{C}$; therefore, the thermal effect was neglected in our numerical simulations.

\section{Geometrical Model and Boundary Conditions}

3.1. Computational Model. Figure 1(a) shows the geometrical model of the modeling sample. The boundary conditions and initial conditions of the tests enable an axisymmetric analysis. The mesh consists of triangle elements. As shown in Figure 1(a), two-dimensional axisymmetric finite element model of $10 \mathrm{~mm}$ (height) $\times 25 \mathrm{~mm}$ (radius), which is identical to the sample size in the laboratory experiment, was established. The entire mesh consists of 760 domain elements and 76 boundary elements. Monitoring points were selected along the axial.

3.2. Modeling Scheme Design and Boundary Conditions. Numerical modeling was performed after the laboratory experiments, which provided essential parameters and proper boundary conditions for the numerical simulations. For the laboratory experiments, the first stage was the water injection test, and the second stage was the gas injection test.
The boundary conditions for the water and gas injection tests are rigid. The numerical modeling scheme was then designed according to results from the laboratory test (Figure 1(b)).

In situ bentonite barrier is confined by the granite host rock. In our numerical modeling, for the axisymmetric model, there are three types of boundary conditions: bottom boundary, top boundary, and lateral boundary. Mechanical boundary conditions require zero displacements in the vertical direction at both the bottom and the top of the sample and zero radial displacement on the lateral side of the sample. The flow boundary conditions contain both water flow and gas flow at different stages. Specifically, the upstream boundary is in direct contact with water $\left(P_{\omega}=1 \mathrm{MPa}\right)$ and gas $\left(P_{g}=0 / 1 / 2 \cdots \mathrm{MPa}\right)$ during the water injection test and the gas injection test, respectively (Figure 1(c)). The downstream boundary is in direct contact with the atmosphere. In order to repeat the laboratory experiments, the results of the previous stage were set as the initial state of the next stage. The values of the main parameters used for numerical modelling are listed in Table 1.

\section{Results and Discussion}

4.1. Water Injection Test. Water was injected from the downstream side of the sample. The overall evolution of the water saturation of the sample as a function of time is shown in Figure 2. Complete water saturation was obtained on the $20^{\text {th }}$ day, which correlates very well with the experimental results. As shown in Figure 3, the water injection volume-time curve becomes linear after 200 hours, which indicates that complete saturation was obtained for the sample after this time. In the laboratory experiment, it is difficult to judge the evolution of the water saturation since the sample cannot be removed from the triaxial cell during the experiment. Thus, the water injection volume-time curve is the only approach to determine water saturation before the gas migration test. Currently, we deem that complete water saturation was obtained as soon as the linear relationship between water volume and time was achieved. The feasibility of this method has been demonstrated in our previous study [33].

With respect to the monitoring points, as shown in Figure 4, point A_5 only needed 7 days to reach full water saturation, whereas the other points needed approximately 15-20 days. This phenomenon is clearly related to the distance of the sample points from the water source. Water was injected from the downstream side, and therefore, less time was needed to become saturated for the monitoring points close to the top surface. However, there is an exception, i.e., point A_1, which is located at the bottom surface. In fact, there exists an interface between the sample and the internal surface of the cell. As soon as water was injected, water could migrate through the interface to arrive at the bottom surface. This phenomenon occurred due to the change in the hydraulic boundary condition of the bottom surface. A similar phenomenon was also found by Liu et al. [34]. The effective water and gas permeability are shown in Figures 5 and 6, from which we can know that the water permeability increased while the gas permeability decreased since 


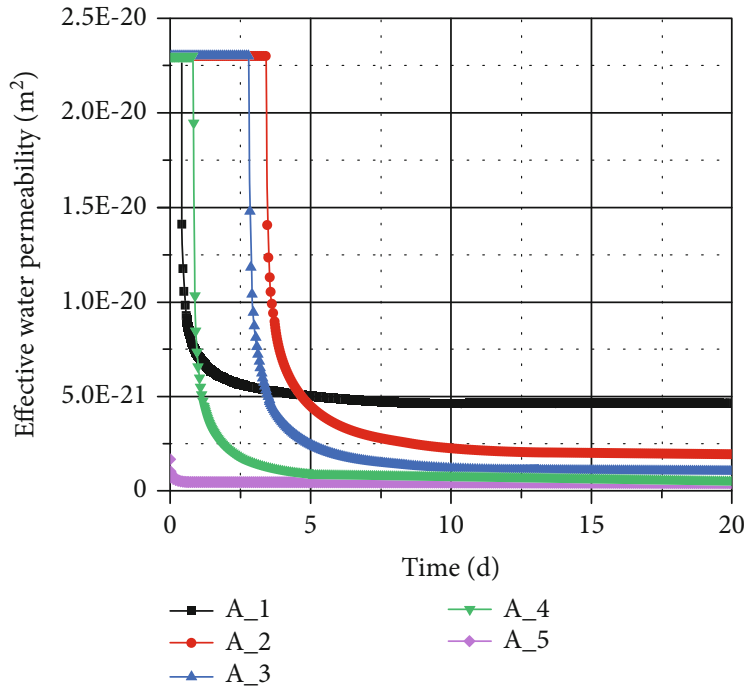

(a)

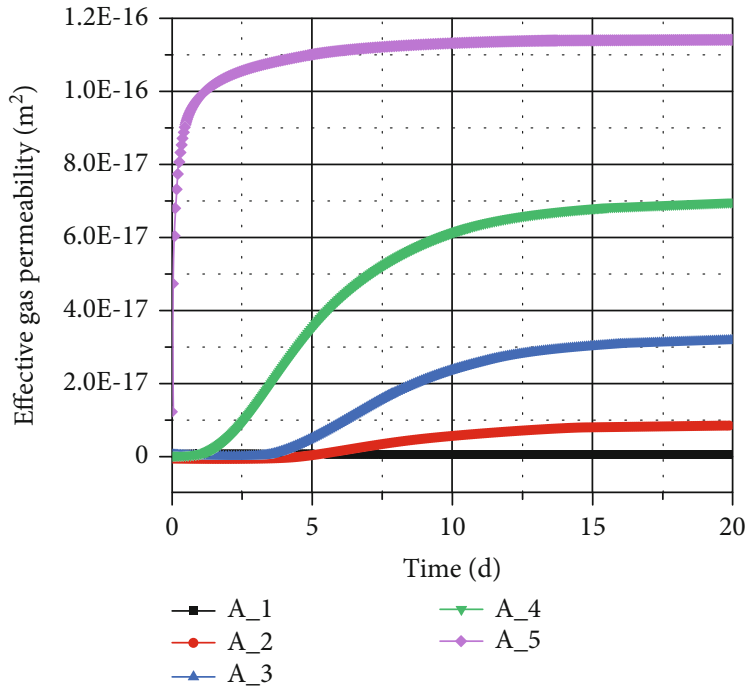

(b)

FIGURE 9: Evolution of the permeability of the monitoring points as a function of time: (a) water permeability and (b) gas permeability.

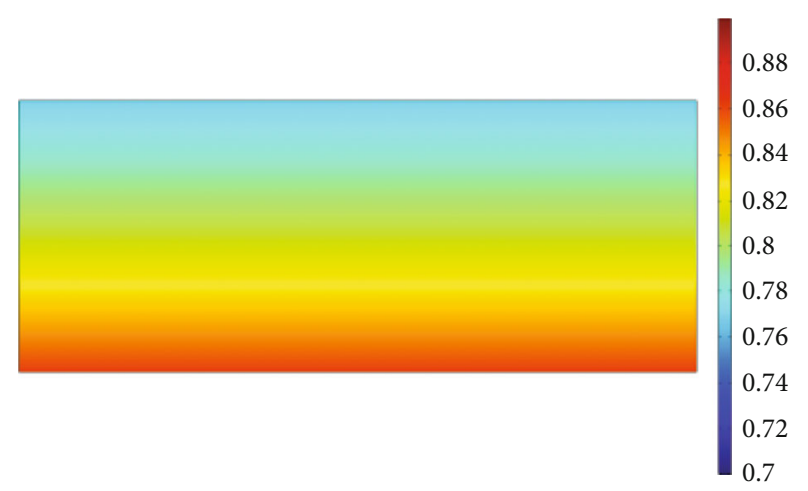

(a)

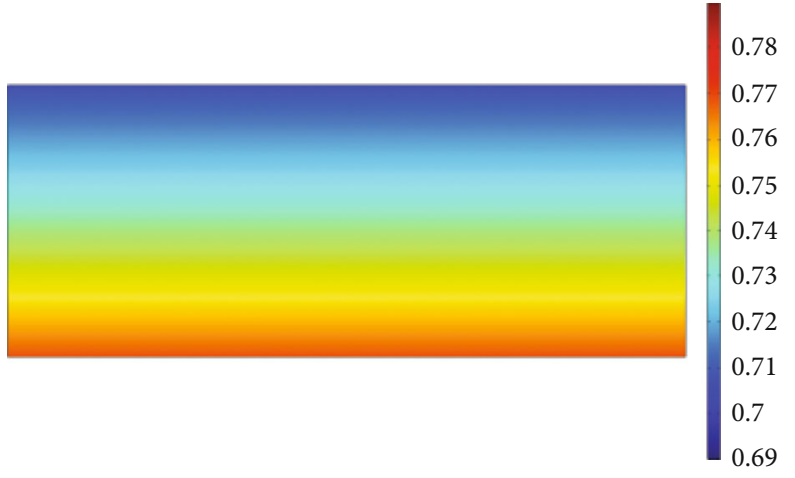

(b)

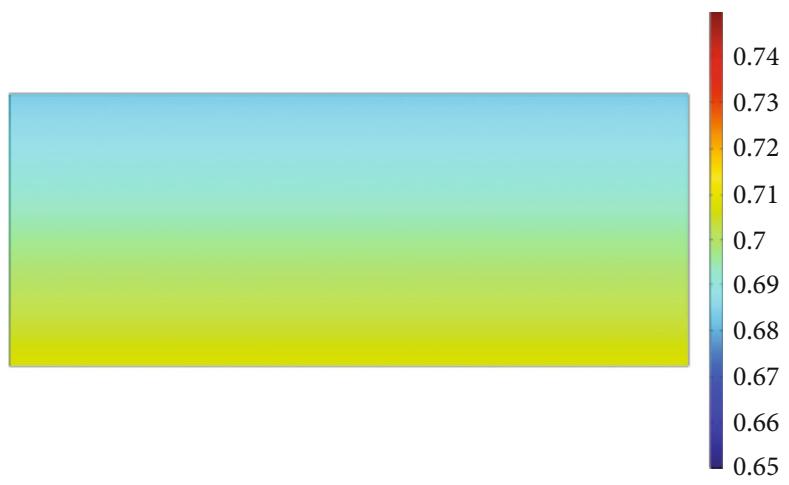

(c)

FIGURE 10: Evolution of water saturation with time on the $2^{\text {nd }}$ day: (a) $P_{g}=2 \mathrm{MPa}$, (b) $P_{g}=3 \mathrm{MPa}$, and (c) $P_{g}=3.5 \mathrm{MPa}$.

the monitoring points gradually reach full water saturation. It should be pointed out that since the water gradually occupies all pore space, the sample can achieve very good gas tightness.

\subsection{Gas Injection Test}

4.2.1. Water Saturation and Permeability with $P_{g}=1 \sim 3.5$ $M P a$. Figure 7 shows the saturation change of the saturated sample under a gas injection pressure of $1 \mathrm{MPa}$. When gas injection began at the upstream side, the saturation of the upper side changed first, and then the saturation was transferred gradually to the lower part. Because of the low gas pressure, the entire process lasted about 20 days when the overall saturation became stable. Since the gas injection was started from the upstream side, it can be seen that after equilibrium, 


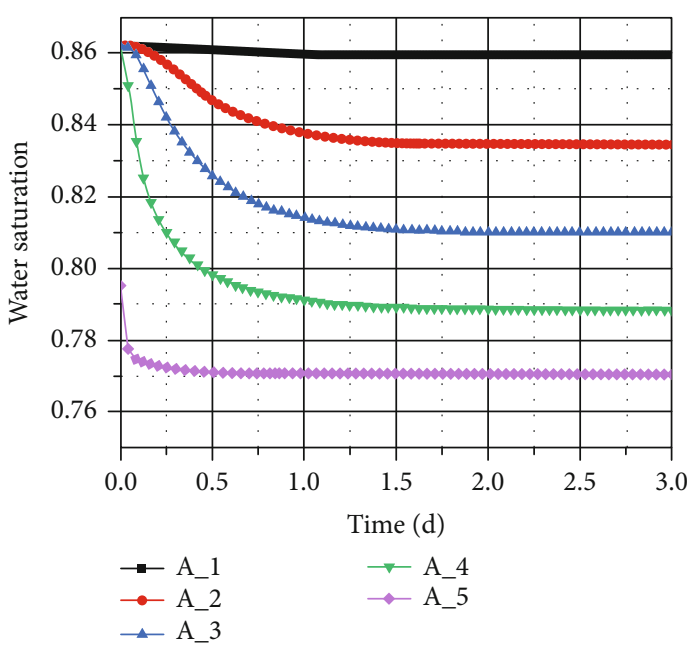

(a)

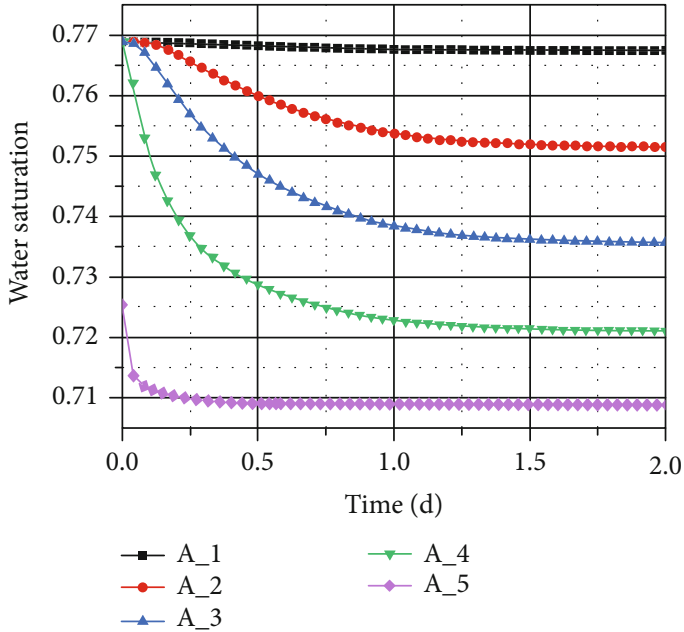

(b)

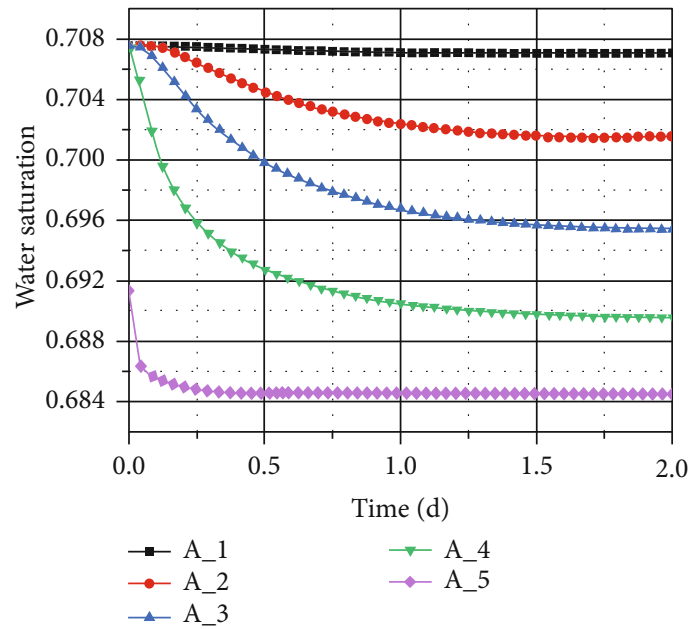

(c)

FIGURE 11: Evolution of the water saturation degree of the monitoring points as a function of time: (a) $P_{g}=2 \mathrm{MPa}$, (b) $P_{g}=3 \mathrm{MPa}$, and (c) $P_{g}=3.5 \mathrm{MPa}$.

the saturation at locations far from the gas injection side was slightly larger than that at the other side. The influence of the gas pressure on the saturation decreased with the increase of the distance from the upstream side. In the repository, gas mainly migrates along the least resistance path, e.g., EDZ (Excavation Damaged Zone) and interfaces between different parts (bentonite blocks, canister, host rock). This means that these parts should be paid special attention for the evaluation of the gas tightness of the whole repository.

Further results can be observed from the monitoring points. The evolution of water saturation with time at the monitoring points is shown in Figure 8. The upper monitoring points took the lead in the change in water saturation, and then with the increase of time, the saturation of the points far from the gas source gradually changed. For the monitoring point A_5, the saturation reached a stable state around the $7^{\text {th }}$ day, while for points A_4 and A_3, it took 16 and 18 days, respectively, to reach a stable state. Since A_5 was close to the gas source, the saturation dropped sharply at the beginning of gas injection, and then it tended to decline slowly and steadily, while the saturation at the other points began to change after 1-4 days of gas migration according to their distance from the gas source. From the upstream side to the downstream side, the time required for reaching stability gradually increased, and it took about 20 days for the entire sample to reach a stable state. On the whole, the saturation of the points far from the gas source was larger than the points near the source after reaching stability.

The permeability change in Figure 9 shows that as the gas injection process progressed, the sample transitioned from a saturated state to an unsaturated state. The water permeability decreased, and the decrease in saturation provided space for gas flow; furthermore, the gas permeability shows an increasing trend. It is particularly important to note that there was a sudden drop in the decrease in water permeability, while the increase in gas permeability was smoother and slower. This may be due to the initial saturation of the specimen. As a whole, the permeability changes were consistent 


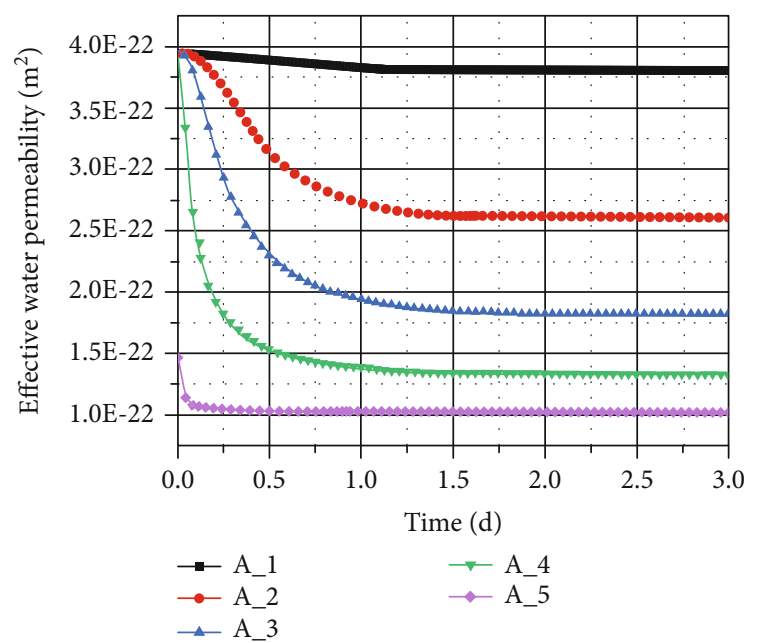

(a)

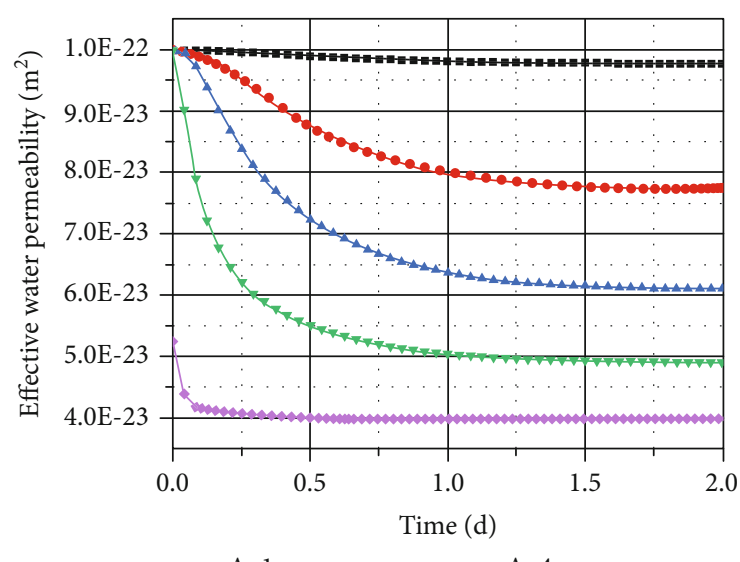

$$
\begin{aligned}
& - \text { A_1 } \\
& \rightarrow \text { A_2 } \\
& \rightarrow \text { A_3 }
\end{aligned}
$$

(b)

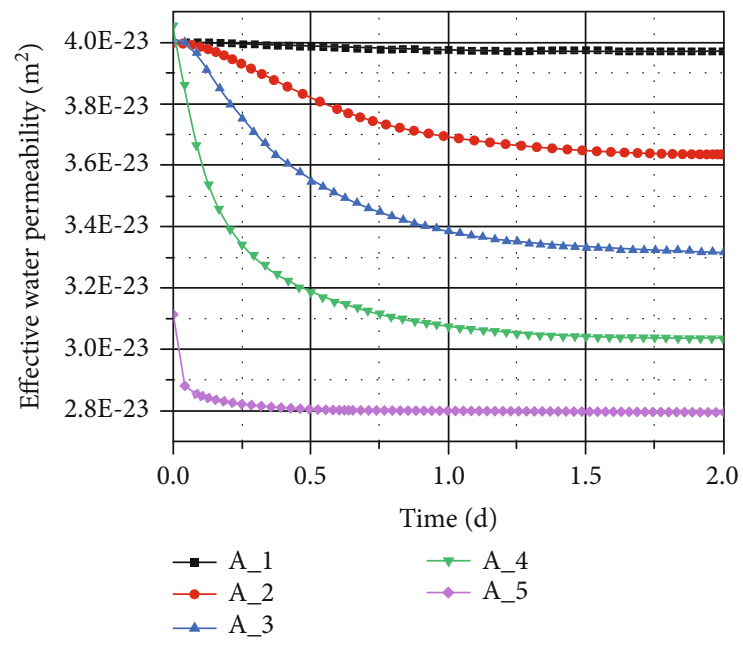

(c)

FIGURE 12: Evolution of the effective water permeability of the monitoring points as a function of time: (a) $P_{g}=2 \mathrm{MPa}$, (b) $P_{g}=3 \mathrm{MPa}$, and (c) $P_{g}=3.5 \mathrm{MPa}$.

with the saturation change; the upstream side took the lead in the change, and the change was gradually transmitted to the downstream side. Finally, a stable fluid migration structure was formed in the sample.

Figure 10 shows the change of saturation after stabilization at gas pressures of 2,3 , and $3.5 \mathrm{MPa}$. In the case of gas injection pressure of $1 \mathrm{MPa}$, it took 20 days for the sample to change from a saturated state to an unsaturated stable state. However, under a gas pressure of 2, 3, and 3.5 MPa, the sample changed from the initial unsaturated state to a state with lower saturation, and the time required to reach stability was rapidly reduced. It took only about two days for the entire sample to reach equilibrium.

Figure 11 shows the variation of the saturation of the monitoring points with time under different gas pressure, which is consistent with the saturation change at the gas pressure of $1 \mathrm{MPa}$; the water saturation near the gas source was smaller than that at other locations, and the water saturation showed gradient descent with the position. The variation in saturation also led to a change in permeability, as shown in Figures 12 and 13; water permeability became smaller while gas permeability became larger. It should be pointed out that the water permeability showed a sudden drop due to the change from the saturated state to the unsaturated state when the gas injection pressure was $1 \mathrm{MPa}$. However, when the gas pressure was further increased, the sample existed in an unsaturated state, and the water permeability showed a slow and smooth reduction.

4.2.2. Water Saturation and Permeability with $P_{g}=4 \sim 8$ $M P a$. As shown in Figure 14, saturation simulation results were obtained after the gas injection pressure was increased to 4,6 , and $8 \mathrm{MPa}$. Compared with the previous gas injection simulation, the difference here is that a higher gas pressure was applied causing lower saturation. This also shows that higher gas pressure has a stronger driving effect on pore water. If the gas pressure is too high, a gas breakthrough will occur. At different stages of gas generation, migration, and 


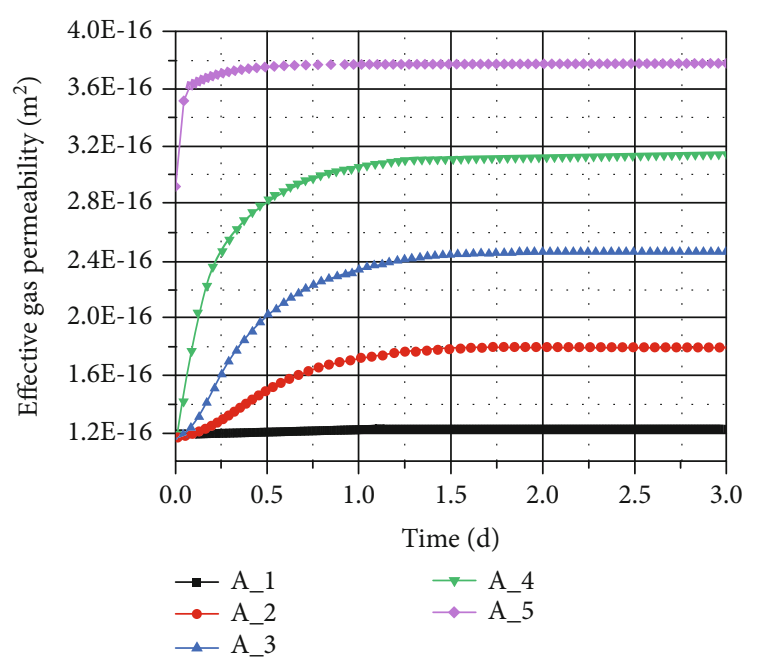

(a)

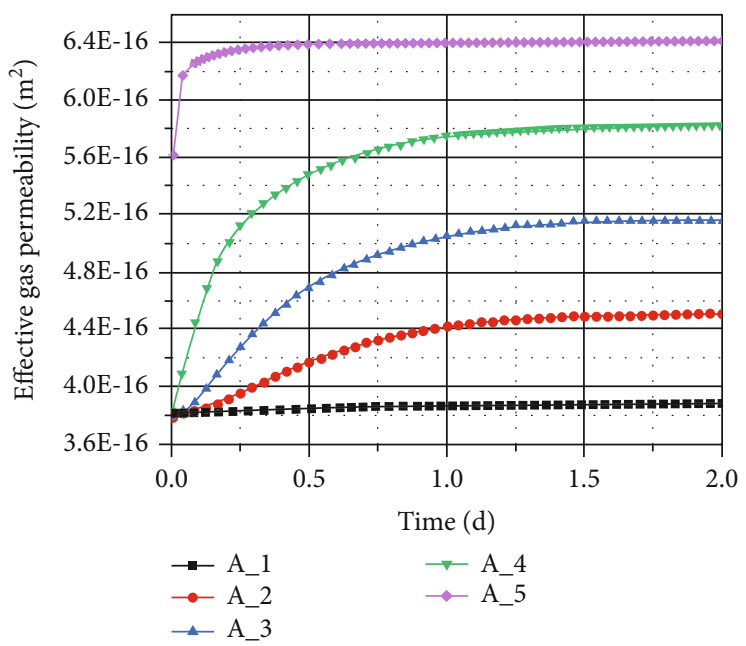

(b)

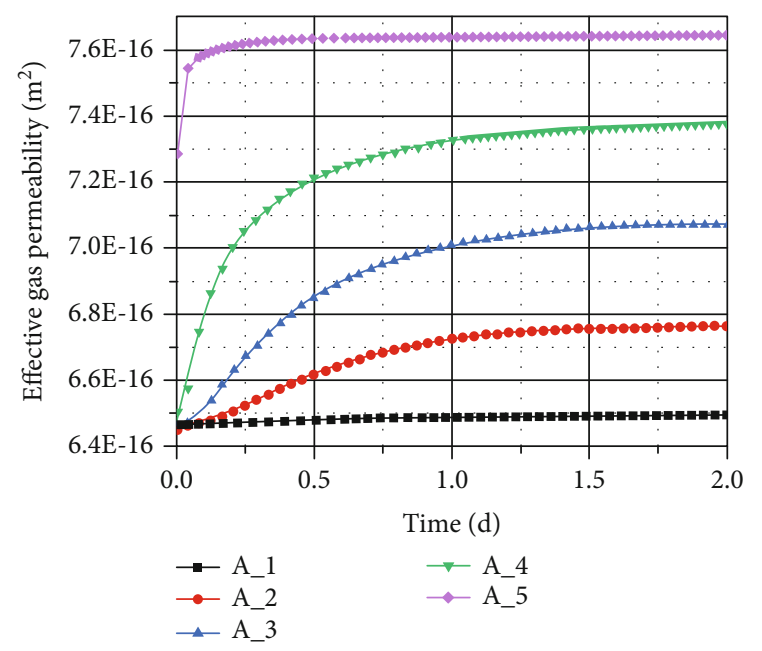

(c)

FIGURE 13: Evolution of the effective gas permeability of the monitoring points as a function of time: (a) $P_{g}=2 \mathrm{MPa}$, (b) $P_{g}=3 \mathrm{MPa}$, and (c) $P_{g}=3.5 \mathrm{MPa}$.

breakthrough, the gas migration mechanism is also different. Therefore, in the subsequent simulation process, it is necessary to consider the different gas transport constitutive equations corresponding to different gas transport mechanisms.

The saturation changes of monitoring points are shown in Figure 15. The change in water saturation shows the gradient distribution since it was affected by the position of the monitoring points. The changes of water permeability and gas permeability are shown in Figures 16 and 17, which are consistent with the abovementioned changes. Water permeability was further reduced, while gas permeability was further increased when greater gas pressure was applied.

4.2.3. Effect of Gas Pressure on Water Saturation and Permeability. In order to further study the influence of gas pressure on fluid migration characteristics, the intermediate monitoring point A_3 was selected as an example. The change of saturation, gas permeability, and water permeability under different gas pressure is shown in Figure 18. As can be seen from the figure, with the increase of gas pressure, the water saturation variation decreased gradually. The saturation values at $6 \mathrm{MPa}$ and $8 \mathrm{MPa}$ are higher because the gas pressure increased was increased by $2 \mathrm{MPa}$ as compared to previous injections before $4 \mathrm{MPa}$ when the pressure of each injection was increased by $1 \mathrm{MPa}(0.5 \mathrm{MPa}$ step by step during 3-4 MPa). It should be pointed out that the total effect of the latter gas injection pressure on the water saturation should be the sum of all the saturation changes before, since the latter injection added a certain gas pressure to the same sample after the previous injection. Therefore, it can be concluded that as the gas pressure increased, the saturation gradually decreased, although with a reduced rate of descent. The effect of the gas pressure increase on the saturation was gradually weakened. This is due to the fact that the water in the soil pore is divided into adsorbed water and free water. The gas drives the free water flow first, while the adsorbed water near the surface of the particle skeleton is firmly locked on the particles, which requires a greater driving force to make it flow [35]. 


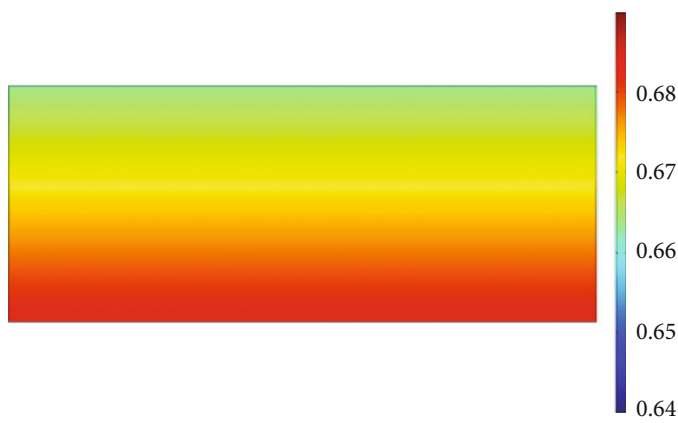

(a)

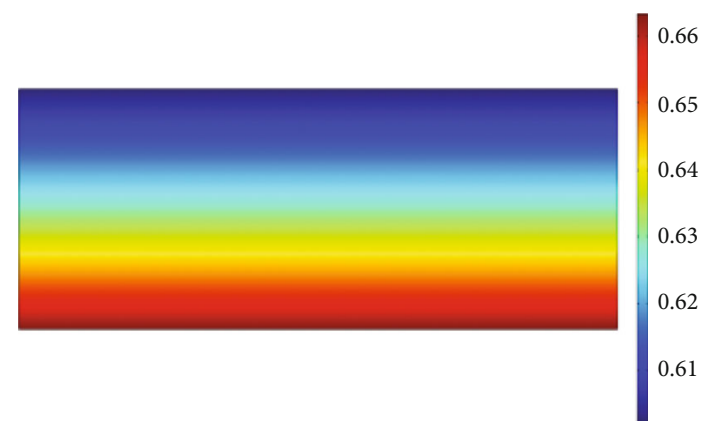

(b)

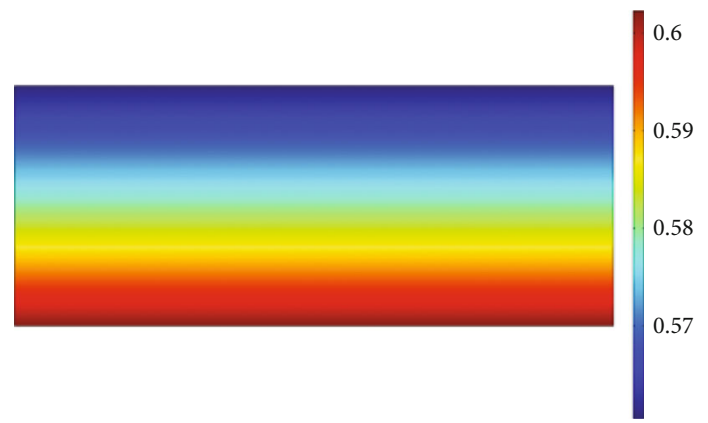

(c)

Figure 14: Evolution of water saturation with time on the $2^{\text {nd }}$ day: (a) $P_{g}=4 \mathrm{MPa}$, (b) $P_{g}=6 \mathrm{MPa}$, and (c) $P_{g}=8 \mathrm{MPa}$.

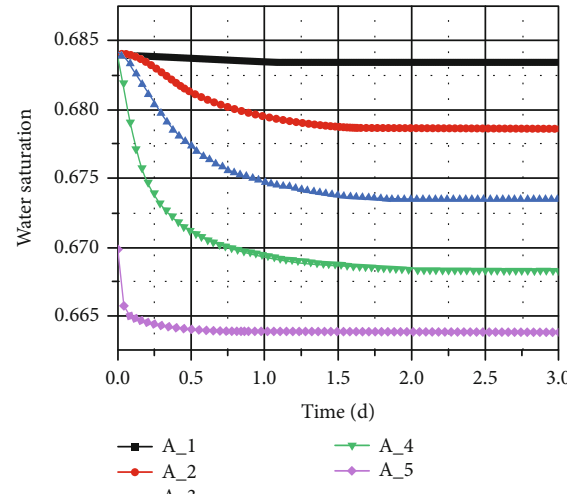

(a)

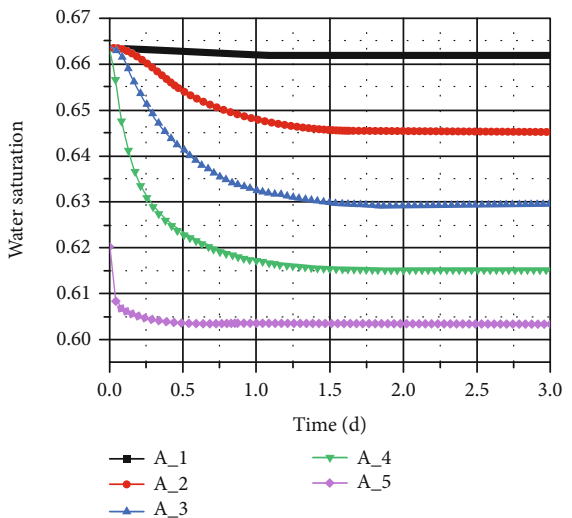

(b)

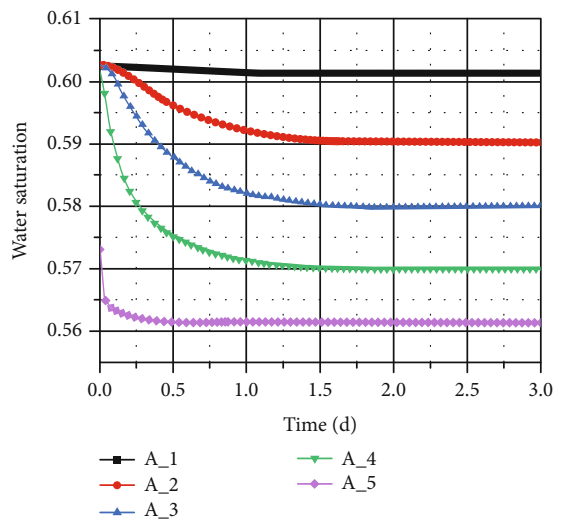

(c)

FIGURE 15: Evolution of the degree of water saturation of the monitoring points as a function of time: (a) $P_{g}=4 \mathrm{MPa}$, (b) $P_{g}=6 \mathrm{MPa}$, and (c) $P_{g}=8 \mathrm{MPa}$. 


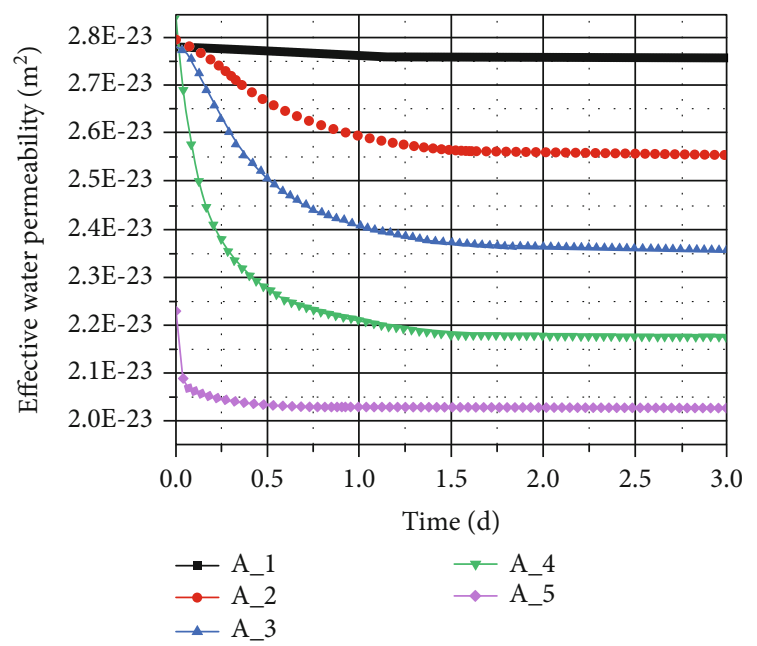

(a)

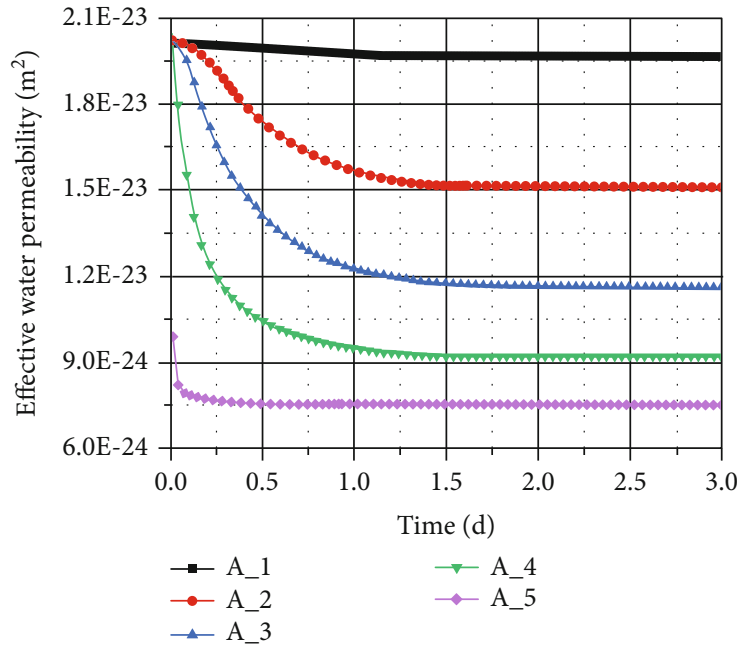

(b)

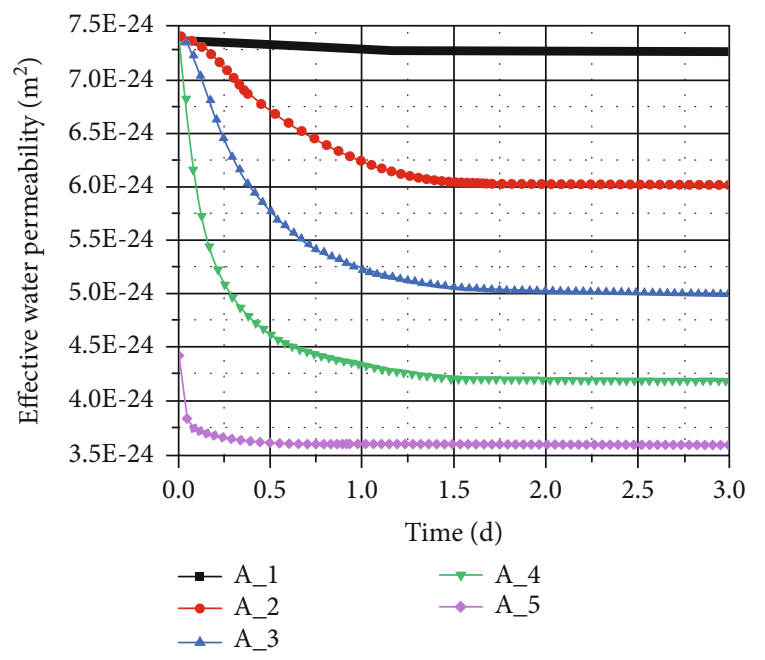

(c)

FIGURE 16: Evolution of effective water permeability of the monitoring points as a function of time: (a) $P_{g}=4 \mathrm{MPa},(\mathrm{b}) P_{g}=6 \mathrm{MPa}$, and (c) $P_{g}=8 \mathrm{MPa}$.

The variation in the permeability at different gas pressures is shown in Figures 18(b) and 18(c). It can be concluded from the figure that the gas permeability increased with the increase of gas pressure, although by different values. The increase in the values when the gas pressure was $6 \mathrm{MPa}$ and $8 \mathrm{MPa}$ is larger, for the same reason as before-that the gas pressure was increased by $2 \mathrm{MPa}$ (from $4 \mathrm{MPa}$ and $6 \mathrm{MPa}$ ), while the previous gas pressure increases were only by $1 \mathrm{MPa}$ or $0.5 \mathrm{MPa}$. In fact, the gas permeability shows a trend of first increasing and then decreasing; when the gas pressure reached $4 \mathrm{MPa}$, the variation reached a critical point, which indicates that as the absolute value of saturation decreased, the amount of change in gas permeability first increased and then decreased. This also corresponds with the gas breakthrough test results. As shown in Figure 19(a), in the gas breakthrough test, when the gas pressure reached $4 \mathrm{MPa}$, a continuous gas breakthrough occurred in the sample after 37 hours. Therefore, time is also very important for the development of gas pathways in the bentonite barrier. Similar phenomenon was also observed in our previous research [24]. In this case, interconnected macropores formed facilitating gas migration, which in turn lead to a decrease in the saturation [36]. However, the water permeability decreased in general as the gas pressure increased. As the saturation decreases, the distribution of water in the sample gradually develops from a continuous form to a discrete form. The residual water is mostly adsorbed on the surface of the particles and tends to be nonflowing.

In general, it can be seen that water and gas have a significant effect on the saturation of buffer/backfill material, and, therefore, affect its sealing performance. In this study, under constant volume condition, during the process of water injection, the sample gradually reached a saturation state, which indicates good gas tightness. Gas injection was then performed on the saturated sample. At low gas pressure, the gas permeability of the sample that is further away from the gas source was less affected by the gas pressure, and the sample as a whole 


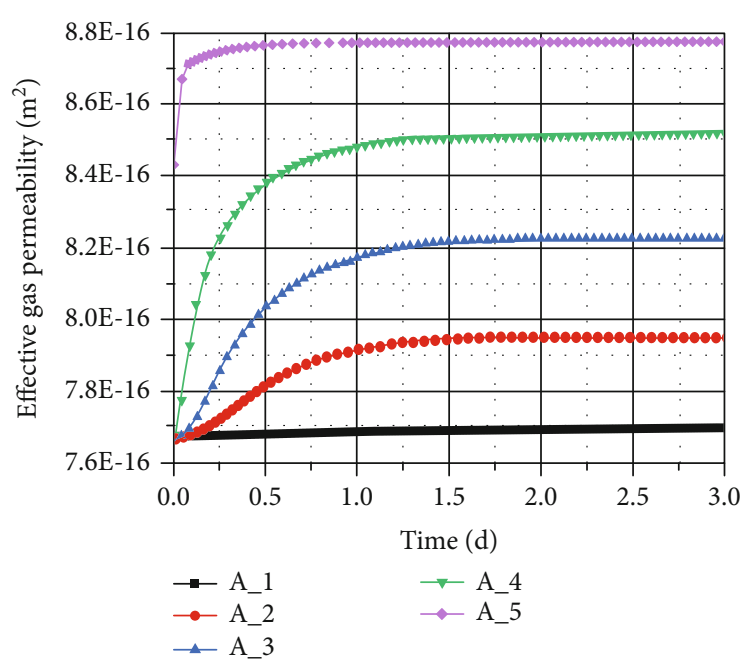

(a)

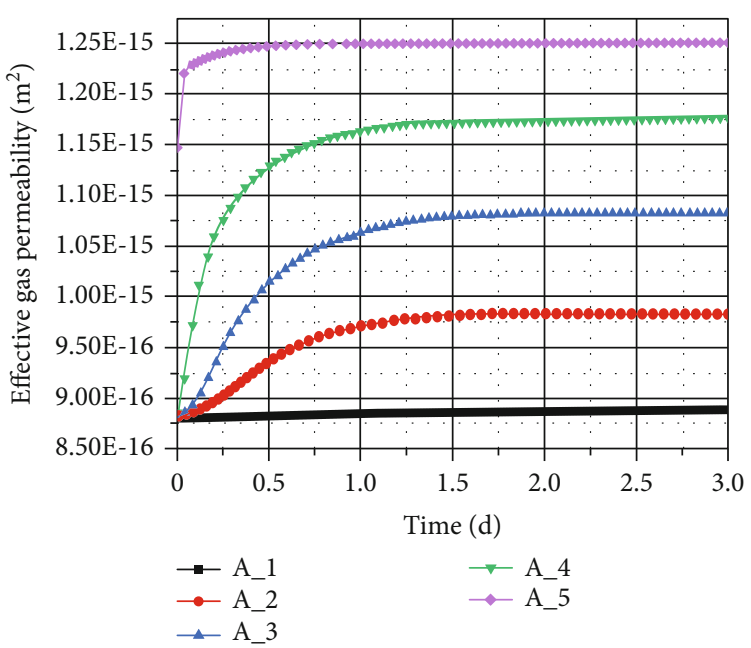

(b)

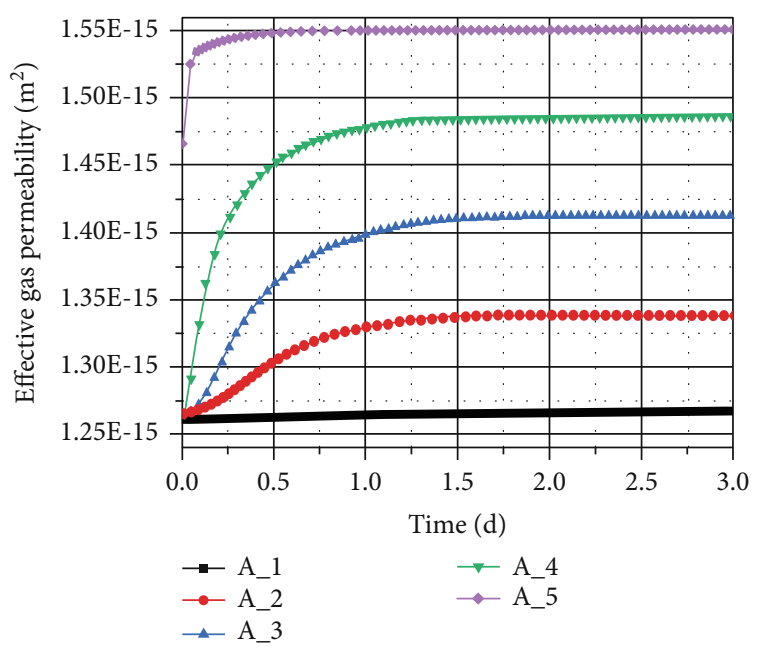

(c)

FIGURE 17: Evolution of effective gas permeability of the monitoring points as a function of time: (a) $P_{g}=4 \mathrm{MPa},(\mathrm{b}) P_{g}=6 \mathrm{MPa}$, and (c) $P_{g}=8 \mathrm{MPa}$.

maintained good gas tightness. With the increase of gas pressure, the saturation became lower, and the pore space was more likely to form a gas flow channel. The overall gas permeation of the sample was greatly changed, and the gas tightness of the sample was lowered. In this study, the boundary condition is fixed. If the boundary condition is free swelling, the bulk volume of bentonite will increase. The change in the pore structure will not only affect the hydration process of bentonite but also affect its gas migration characteristics [33, 37].

\section{Conclusions}

Numerical simulation is an effective means to understand the process of water and gas migration in bentonite buffer. In this study, the simulation of water injection and subsequent gas injection shows that during the process of water injection, the locations of the samples that were closer to the water source were first saturated. With the passage of time, the entire structure reached saturation showing that the bentonite sample is able to play a good sealing role.
For saturated soil, it took a long time for the sample to transition from a saturated state to an unsaturated stable state under $1 \mathrm{MPa}$ gas pressure. With the increase in the gas injection pressure, the saturation further decreased, and the time required to reach stability decreased. Under constant volume condition, when the gas pressure was low, the gas permeability of the sample at the portion further away from the gas source was less affected by gas pressure, and the whole structure still showed good sealing properties.

As the gas pressure increased, the saturation decreased further, but the amount of decline in the saturation decreased. The influence of increasing the gas pressure on saturation decreased gradually. One reason for this is that the internal water is composed of free water and absorbed water. The free water is first driven to flow, while a greater driving forced is needed for absorbed water as it is firmly absorbed on the particles. Compared to the change in permeability, when the sample changed from a saturated state to an unsaturated state, with increasing gas pressure, the gas permeability first increased and then decreased, and the gas pressure of $4 \mathrm{MPa}$ was the 


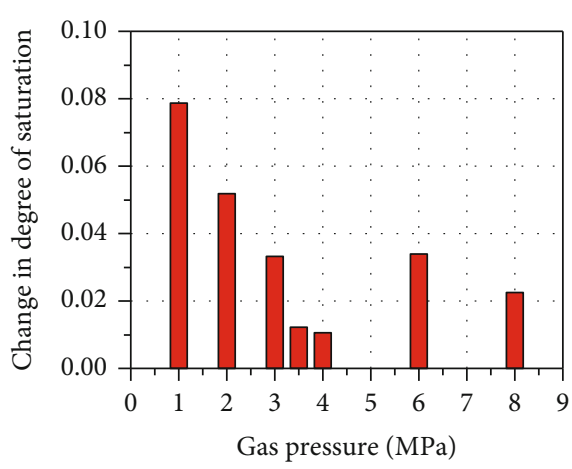

(a)

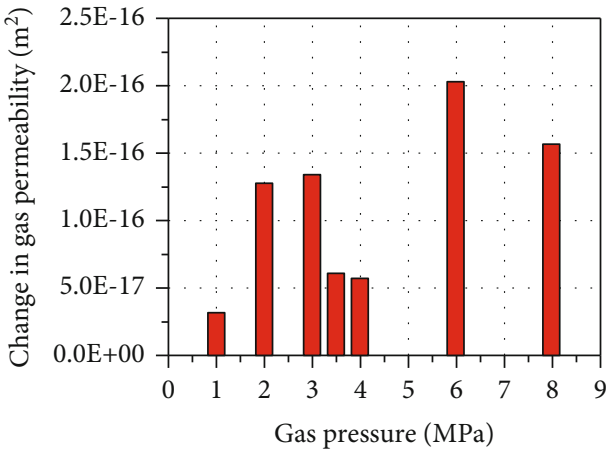

(b)

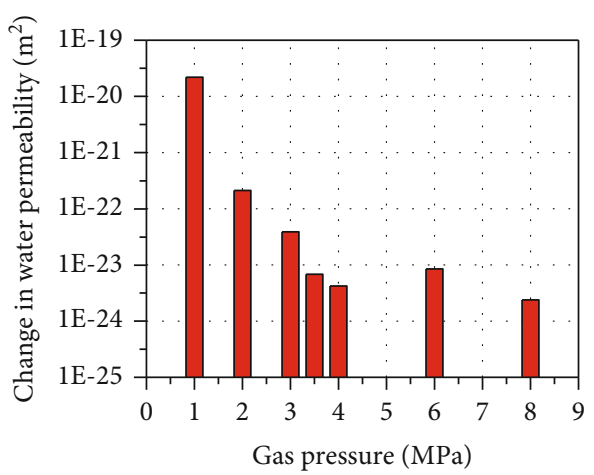

(c)

FIGURE 18: Change of point A_3 under different pressure: (a) saturation, (b) gas permeability, and (c) water permeability.

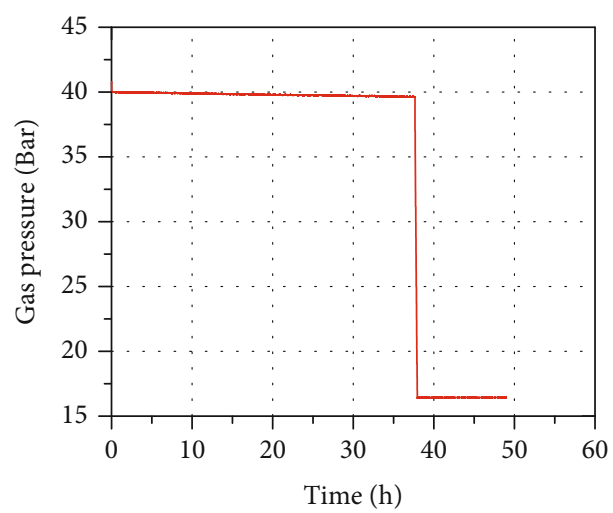

(a)

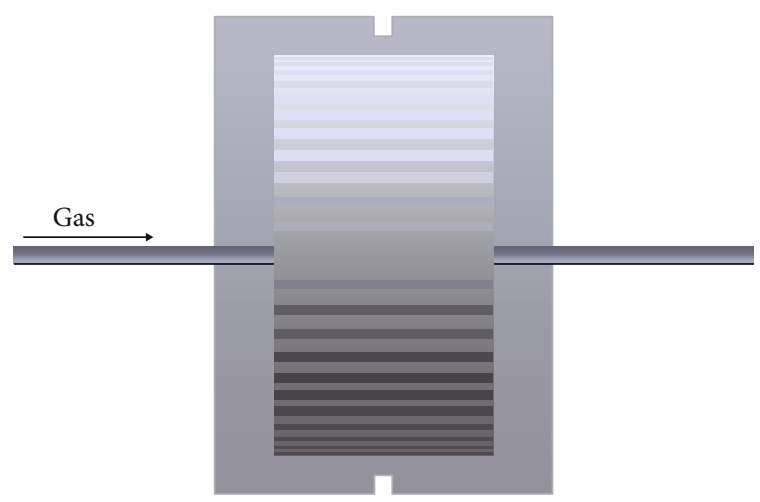

(b)

FIGURE 19: Gas breakthrough experiment: (a) gas pressure changes with time and (b) Schematic diagram of experiment equipment.

critical point. Gas breakthrough occurred when the gas pressure reached $4 \mathrm{MPa}$ in the gas injection test process. Interconnected pores for gas migration were formed inside the sample, resulting in a decrease in the water saturation, and the water permeability was reduced in general.

\section{Data Availability}

The data used to support the findings of this study are available from the corresponding author upon request.

\section{Conflicts of Interest}

The author(s) declare(s) that they have no conflicts of interest.

\section{Acknowledgments}

The authors are grateful for the support provided by the Fundamental Research Funds for the Central Universities (China University of Mining and Technology) (2019XKQYMS19). 


\section{References}

[1] L. Chen, Y. M. Liu, J. Wang et al., "Investigation of the thermal-hydro-mechanical (THM) behavior of GMZ bentonite in the China-mock-up test," Engineering Geology, vol. 172, pp. 57-68, 2014.

[2] Y. G. Chen, X. X. Dong, X. D. Zhang, W. M. Ye, and Y. J. Cui, "Combined thermal and saline effects on the swelling pressure of densely compacted GMZ bentonite," Applied Clay Science, vol. 166, pp. 318-326, 2018.

[3] Y. Xue, F. N. Dang, F. Shi, R. J. Li, and Z. Z. Cao, "Evaluation of gas migration and rock damage characteristics for underground nuclear waste storage based on a coupled model," Science And Technology Of Nuclear Installations, vol. 2018, Article ID 2973279, 10 pages, 2018.

[4] J. Wang, L. Chen, R. Su, and X. G. Zhao, “The Beishan underground research laboratory for geological disposal of highlevel radioactive waste in China: Planning, site selection, site characterization and in situ tests," Journal of Rock Mechanics and Geotechnical Engineering, vol. 10, no. 3, pp. 411-435, 2018.

[5] Y. He, W. M. Ye, Y. G. Chen, K. N. Zhang, and D. Y. Wu, "Effects of $\mathrm{NaCl}$ solution on the swelling and shrinkage behavior of compacted bentonite under one-dimensional conditions," Bulletin of Engineering Geology and the Environment, vol. 79, no. 1, pp. 399-410, 2020.

[6] X. Pintado, E. Romero, J. Suriol, A. Lloret, and B. N. Madhusudhan, "Small-strain shear stiffness of compacted bentonites for engineered barrier system," Geomechanics for Energy and the Environment, vol. 18, pp. 1-12, 2020.

[7] W. M. Ye, N. C. Borrell, J. Y. Zhu, B. Chen, and Y. G. Chen, "Advances on the investigation of the hydraulic behavior of compacted GMZ bentonite," Engineering Geology, vol. 169, pp. 41-49, 2014.

[8] Y. G. Chen, Z. Sun, Y. J. Cui, W. M. Ye, and Q. H. Liu, "Effect of cement solutions on the swelling pressure of compacted GMZ bentonite at different temperatures," Construction and Building Materials, vol. 229, p. 116872, 2019.

[9] A. Ferrari, M. Rosone, M. Ziccarelli, and S. B. Giger, "The shear strength of Opalinus clay shale in the remoulded state," Geomechanics for Energy and the Environment, vol. 21, p. 100142, 2020.

[10] J. F. Harrington, R. de la Vaissiere, D. J. Noy, R. J. Cuss, and J. Talandier, "Gas flow in Callovo-Oxfordian claystone (COx): results from laboratory and field-scale measurements," Mineralogical Magazine, vol. 76, no. 8, pp. 3303-3318, 2012.

[11] J. F. Liu, Y. Wu, C. Z. Cai et al., "Investigation into water retention and gas permeability of Opalinus clay," Environmental Earth Sciences, vol. 77, no. 5, pp. 1-13, 2018.

[12] C. A. Davy, F. Skoczylas, P. Lebon, and T. Dubois, "Gas migration properties through a bentonite/argillite interface," Applied Clay Science, vol. 42, no. 3-4, pp. 639-648, 2009.

[13] J. F. Harrington, C. C. Graham, R. J. Cuss, and S. Norris, "Gas network development in compact bentonite: key controls on the stability of flow pathways," Geofluids, vol. 2019, Article ID 3815095, 19 pages, 2019.

[14] S. T. Horseman, J. F. Harrington, and P. Sellin, "Gas migration in clay barriers," Engineering Geology, vol. 54, no. 1-2, pp. 139149, 1999.

[15] B. Carbonell, M. V. Villar, P. L. Martin, and C. Gutierrez-Alvarez, "Gas transport in compacted bentonite after 18 years under barrier conditions," Geomechanics for Energy and the Environment, vol. 17, pp. 66-74, 2019.

[16] M. S. Biju and D. N. Arnepalli, "Effect of biopolymers on permeability of sand-bentonite mixtures," Journal of Rock Mechanics and Geotechnical Engineering, vol. 12, no. 5, pp. 1093-1102, 2020.

[17] C. A. Davy, F. Skoczylas, J. D. Barnichon, and P. Lebon, "Permeability of macro-cracked argillite under confinement: as and water testing," Physics and Chemistry of the Earth, Parts $A / B / C$, vol. 32, no. 8-14, pp. 667-680, 2007.

[18] J. F. Liu, H. Y. Ni, X. L. Cao, L. K. Ma, J. N. Guo, and X. Chen, "Laboratory investigation on gas permeability of compacted GMZ bentonite under a coupled hydraulic-mechanical effect," Engineering Geology, vol. 276, p. 105761, 2020.

[19] C. L. Zhang and T. Rothfuchs, "Damage and sealing of clay rocks detected by measurements of gas permeability," Physics and Chemistry of the Earth, vol. 33, pp. S363-S373, 2008.

[20] C. Gallé, "Gas breakthrough pressure in compacted Fo-Ca clay and interfacial gas overpressure in waste disposal context," Applied Clay Science, vol. 17, no. 1-2, pp. 85-97, 2000.

[21] A. Hildenbrand, S. Schlömer, and B. M. Krooss, "Gas breakthrough experiments on fine-grained sedimentary rocks," Geofluids, vol. 2, no. 1, 23 pages, 2002.

[22] K. Tanai, T. Kanno, and C. Gallé, "Experimental study of gas permeabilities and breakthrough pressures in clays," MRS Proceedings, vol. 465, pp. 995-1002, 1996.

[23] C. L. Zhang and K.-P. Kröhn, "Sealing behaviour of crushed claystone-bentonite mixtures," Geomechanics for Energy and the Environment, vol. 17, pp. 90-105, 2019.

[24] J. F. Liu, Y. Song, F. Skoczylas, and J. Liu, "Gas migration through water-saturated bentonite-sand mixtures, COx argillite, and their interfaces," Canadian Geotechnical Journal, vol. 53, no. 1, pp. 60-71, 2016.

[25] C. P. Kumar, "Modelling of unsaturated flow," in National Conference on "Modern Trends in Water Resources Development and Environmental Management", Vellore Institute of Technology, 2002.

[26] P. Ngnepieba, D. X. L. François, A. Boukong et al., "Identification de paramètres: une application à l'équation de Richards," Arima, vol. 1, pp. 127-157, 2002.

[27] L. A. Richards, "Capillary conduction of liquids through porous mediums," Journal of Applied Physics, vol. 1, pp. 318333, 1931.

[28] P. S. D. Laplace, Traite de mechanique celeste, Gauthier Villars, Paris, 1808.

[29] L. Thomas, D. L. Katz, and M. R. Tek, "Threshold pressure phenomena in porous media," Society of Petroleum Engineers Journal, vol. 8, no. 2, pp. 174-184, 2013.

[30] T. Young, "An essay on the cohesion of fluids," Philosophical Transactions of the Royal Society of London, vol. 95, pp. 6587, 1805.

[31] M. T. V. Genuchten, "A closed-form equation for predicting the hydraulic conductivity of unsaturated soils," Soil Science Society of America Journal, vol. 44, no. 5, pp. 892-898, 1980.

[32] Y. Mualem, "A new model for predicting the hydraulic conductivity of unsaturated porous media," Water Resources Research, vol. 12, no. 3, pp. 513-522, 1976.

[33] J. F. Liu, S. B. Song, H. Y. Ni et al., "Research on gas migration properties in a saturated bentonite/sand mixture under flexible boundary conditions," Soils and Foundations, vol. 58, no. 1, pp. 97-109, 2018. 
[34] J. F. Liu, S. B. Song, J. Liu et al., "A numerical investigation on the effect of gas pressure on the water saturation of compacted bentonite-sand samples," Geofluids, vol. 113, no. 3, 117 pages, 2017.

[35] W. Sun, S. Da, L. Fang, and S. Liu, "Soil-water characteristics of Gaomiaozi bentonite by vapour equilibrium technique," Journal of Rock Mechanics and Geotechnical Engineering, vol. 6, no. 1, pp. 48-54, 2014.

[36] L. Xu, W. M. Ye, and B. Ye, "Gas breakthrough in saturated compacted GaoMiaoZi (GMZ) bentonite under rigid boundary conditions," Canadian Geotechnical Journal, vol. 54, no. 8, pp. 1139-1149, 2017.

[37] S. B. Song, J. F. Liu, D. S. Yang et al., "Pore structure characterization and permeability prediction of coal samples based on SEM images," Journal of Natural Gas Science and Engineering, vol. 67, pp. 160-171, 2019.

[38] L. Y. Jia, Y. G. Chen, W. M. Ye, and Y. J. Cui, "Effects of a simulated gap on anisotropic swelling pressure of compacted GMZ bentonite," Engineering Geology, vol. 248, pp. 155-163, 2019.

[39] J. Liu, S. Song, X. Cao et al., "Determination of full-scale pore size distribution of Gaomiaozi bentonite and its permeability prediction," Journal of Rock Mechanics and Geotechnical Engineering, vol. 12, no. 2, pp. 403-413, 2020.

[40] J. F. Liu, J. N. Guo, H. Y. Ni, Q. Zhang, and F. Skoczylas, "Swelling and gas transport characteristics of saturated compacted bentonite/sand samples considering the scale effect," Geomechanics for Energy and the Environment, p. 100227, 2020. 